\title{
O ESTUDO EM GRUPO COMO MÉTODO DE ENSINO EM PSICOLOGIA
}

\author{
Prof." Ivonete Batista Xavier*
}

RBEn/09

XAVIER, I.B. - O estudo em grupo como método de ensino em Psicologia. Rev. Bras. Enf.; RJ, $28: 65-70,1975$.

\section{I - INTRODUÇÃO}

Somos partidárias da Escola Ativa, que procura unir informação à formação, conhecimento à própria vida.

A enfermeira como profissional lidará sempre com pessoas, trabalhará em equipe. Consequentemente a escola, deve proporcionar à estudante oportunidade para aprender a comportar-se em grupo.

A nosso ver o estudo em grupo, técnica eminentemente ativa, quando bem conduzido, tem condições de atingir os objetivos delineados: propiciar aos alunos o aprendizado do convívio social e desenvolver a criatividade que existe em cada um.

Acreditávamos na técnica do estudo em grupo, ao mesmo tempo que era imenso nosso desejo de mudar, de substituir aquelas aulas expositivas, rotineiras e cansativas (para nós e para os alunos), por aulas "vivas", mais dinâmicas e que envolvessem toda a turma.

O presente trabalho desenvolveu-se na Faculdade de Enfermagem da Uni- versidade Federal de Pernambuco, em 1969.

\section{II - ATIVIDADES DIDÁTICAS DESENVOLVIDAS NO DECORRER DO ANO LETIVO}

Cabia à disciplina de Psicologia, uma carga horária de 90 horas durante os dois semestres.

As atividades didáticas realizadas no 1. ${ }^{\circ}$ semestre foram:
a) aula expositiva - Psicologia; con- ceito, métodos, aplicações;
b) estudo em grupo - Hereditarie- dade e Ambiente;
c) aula expositiva - "Como realizar pesquisa bibliográfica” (dada pela bibliotecária-chefe da Escola de Enfermagem);
d) estudo em grupo - Emoções, Re- lações psicossomáticas do orga- nismo;
e) estudo em grupo - Motivação;

- Professora de Psicologia da Faculdade de Enfermagem da Universidade Federal de Pernambuco, Recife, 1969. 
XAVIER, I.B. - O estudo em grupo como método de ensino em Psicologia. Rev. Bras.

Enf.; RJ, 28 : 65-70, 1975.

f) estudo em grupo - Inteligência (foi realizada uma visita a uma Escola de Crianças Excepcionais e solicitado um relatório dos alunos a par do estudo teórico em grupo) ;

g) aula expositiva - Personalidade.

$2 .^{\circ}$ semestre:

a) estudo em grupo - Importância da vida pré-natal e nascimento;

b) aula teórica - Caracteres gerais da infância;

c) estudo em grupo - O comportatamento dos pais e a influência da da família no desenvolvimento da criança; (foi realizada uma projeção cinematográfica sobre o tema, seguida de discussão pelo grupo a par do estudo teórico);

d) estudo em grupo - Reações específicas da criança doente; (foi realizada uma visita ao Instituto de Medicina Infantil de Pernambuco e solicitado um relatório dos grupes);

e) estudo em grupo - Adolescência: significado e caracteres gerais;

Foi realizado pelos alunos um painel, no "hall" da Escola, sendo convidados professores e alunos de outras séries e cursos;

f) estudo em grupo - A idade adulta. características da mautridade.

\section{III - OBJETIVO DESTE TRABALHO}

O objetivo deste trabalho foi:

a) investigar o grau de adaptação dos alunos à técnica do estudo em grupo;

b) estimar a eficácia do método de ensino a ser aplicado pela disciplina de Psicologia;

c) averiguar a possibilidade de estendê-lo a outras disciplinas do curso geral de graduação em Enfermagem.
IV - MéTODO

No primeiro contato com os alunos, ao início do ano letivo, expusemos, os objetivos da disciplina de Psicologia, os assuntos a serem estudados, bem como a metodologia que prentendíamos empregar no corrente ano, sistema de avaliação, etc. Procuramos motivar os 51 alunos matriculados a estudar em equipe, discorrendo brevemente sobre suas vantagens.

Na semana seguinte, os grupos já estavam formados (grupos naturais). Após 30 dias aproximadamente, utilizamos a técnica do sociograma tendo havido, como era de se esperar, mudanças na composição dos grupos.

No primeiro semestre registramos inicialmente a formação de 7 grupos (6 grupos de 5 alunos cada um e 1 grupo com 6 alunos), registramos ainda a formação de 9 grupos (6 grupos de 6 alunos e 3 grupos de 5 alunos); finalmente, 6 grupos de 5 alunos e 3 grupos de 6 alunos. Durante o segundo semestre, observamos maior estabilidade na composição dos grupos, as 9 equipes anteriores se conservavam, tendo a freqüência geral dos alunos oscilado entre 46 e 48 .

Dentro de um espírito altamente democrático, cada grupo escolheu um representante. Ao chefe de cada grupo distribuímos uma folha mimeografada, contendo instruções sobre sua atuação como coordenador geral, suas relações entre os membros do grupo e deste com a professora. Além disso, foram distribuídos folhetos sobre "como deve agir um líder". A todos os alunos distribuímos cópias de "como se deve trabalhar em equipe".

Coube à professora, antes de cada estudo de grupo, elaborar o roteiro da unidade a ser estudada, indicar a bibliografia, supervisionar e sanar as dúvidas durante o desenvolvimento do trabalho. Embora não se fizesse chamada ano- 
XAVIER, I.B. - O estudo em grupo como método de ensino em Psicologia. Rev. Bras. Enf.; RJ, 28 : 65-70, 1975.

tamos, para nosso controle, as atitudes dos alunos dentro dos grupos tais como: assiduidade, pontualidade, liderança, método de trabalho, nível de participação, etc.

No primeiro semestre adotamos o seguinte critério de trabalho: pesquisa do assunto a ser estudado em grupo e redação final, em grupo. No segundo semestre a pesquisa inicial continuou a ser em grupo, porém a redação final passou a ser feita individualmente. Esta mudança ocorreu porque observamos alunos que participavam muito pouco dos trabalhos de sua equipe; fato, aliás, comprovado pelos próprios colegas, quando da aplicação de um questionário no fim do primeiro semestre.

Enfrentamos sérias dificuldades quanto a localização do grupos, a turma era numerosa, vale dizer, a maior que a Escola já recebeu. A princípio os grupos se acamodavam nas salas de aulas contíguas, quando desocupadas, e nas dependências da Biblioteca, exigindo muita atividade e energia por parte da professora. No segundo semestre conseguimos congregar toda a turma nas dependências da Biblioteca.

Observações pessoais e informações verbais colhidas através dos alunos, permitiram-nos elaborar um questionário que apresentamos seguido dos resultados.

\section{V - QUESTIONÁRIO E RESULTADOS}

1. Identificação do grupo (total) $-54 \%$ dos alunos se encontravam na faixa etária de $21-23$ anos; $22 \%$ entre $18-20$ anos; $91 \%$ dos alunos são do sexo feminino e $9 \%$ casadas, enquanto $9 \%$ é constituído pelo sexo masculino, todos solteiros.

2. Método de ensino - apresentamos abaixo, os resultados obtidos da análise das respostas às perguntas sobre o método de ensino:

a) Que acha, até o momento, do método de ensino utilizado nas aulas de Psicologia?

- ótimo - $55 \%$

- bom - $41 \%$

- mau -

- péssimo -

- em branco $-4 \%$

b) Já trabalhou em equipe alguma vez? E de quantas equipes participou até agora?

- 76\% já tinham experiência anterior em trabalho de grupo; destes $65 \%$ participaram de uma única equipe; $9 \%$ de duas equipes e $2 \%$ de de três equipes.

- $15 \%$ que nunca estudaram em grupo, participaram de uma só equipe, enquanto $2 \%$ participaram de duas equipes.

- 7\% não responderam a questão.

c) Está adaptado ao seu grupo atual?

$-\operatorname{Sim}-85 \%$; não $-15 \%$

d) Seu grupo de trabalho tem problemas?

— os adaptados: $\operatorname{sim} 46 \%$; Não - 39\%

— os não adaptados: $\operatorname{sim}-15 \%$; não - 
XAVIER, I.B. - O estudo em grupo como método de ensino em Psicologia. Rev. Bras. Enf.; RJ, $28: 65-70,1975$.

e) Problemas apresentados pelos grupos:

- falta đe pontualidade - adaptados - 35\%; não adaptados $-31 \%$

— falta de participação - adaptados - 33\%; não adaptados - $12 \%$

- irresponsabilidade - adaptados - 23\%; não adaptados $-12 \%$

- falta de entrosamento - adaptados - 9\%; não adaptados - $31 \%$

- falta de tempo - adaptados - -; não adaptados - 6\%

- estudar à última hora - adaptados - -; não adaptados - 6\%

Obs. -- Os alunos não adaptados ainda mencionaram como motivos de inadaptação, embora em proporções muito reduzidas, os seguintes:

- diferenças de idade (uma vez); diferenças de temperamento (uma vez); falta de apoio às opiniões individuais (duas vezes); falta de experiência de estudar em grupo (uma vez); falta de interesse (uma vez); imaturidade (uma vez);

- ainda foram lembrados os motivos por nós sugeridos: irresponsabilidade, falta de pontualidade, falta de participação e falta de entrosamento, (uma vez cada um).

f) Você acha que estes motivos interferem na produtividade do grupo? - sim - 70\%; não - 9\% - em branco - 22\%

g) No seu entender, quais seriam as vantagens e desvantagens de se estudar em grupo?

- 4\% do total dos alunos não responderam a esta questão;

- $41 \%$ do total dos alunos não referiram desvantagens;

Vejamos primeiro as vantagens mencionadas.

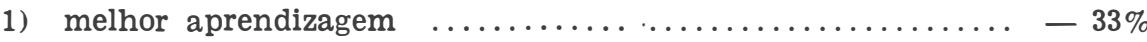

2) possibilita discussão e troca de idéias $\ldots \ldots \ldots \ldots \ldots-13 \%$

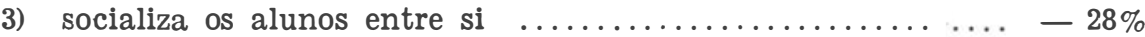

4) oportunidade de melhorar a personalidade $\ldots \ldots \ldots \ldots-8 \%$

5) oportunidade de se conhecer e aos colegas ............ $-4 \%$

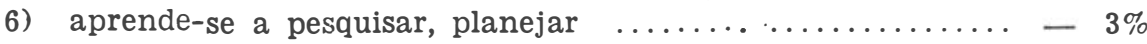

7) participação mais ativa na matéria $\ldots \ldots \ldots \ldots \ldots \ldots \ldots \ldots \ldots \ldots$

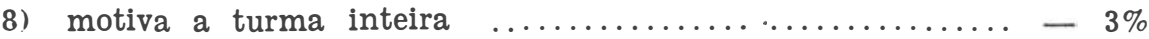

9) adquire-se senso de responsabilidade $\ldots \ldots \ldots \ldots \ldots \ldots \ldots \ldots$

10) adquire-se hábitos de conversação $\ldots \ldots \ldots \ldots \ldots \ldots \ldots \ldots \ldots \ldots$

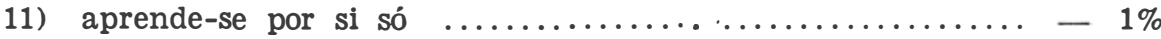

Vejamos as desvantagens referidas pelo grupo:

1) falta de participação de alguns membros $\ldots \ldots \ldots \ldots \ldots-28 \%$

2) falta de entrosamento entre os membros ............ - $22 \%$

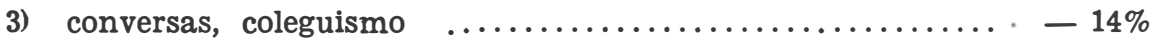

4) Irresponsabilidade" (falta de pontualidade, abuso das horas

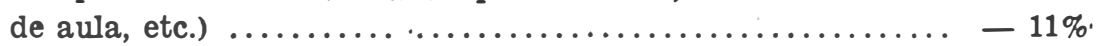

5) dificuldade de entender assuntos complexos ..........

6) liderança de certos elementos do grupo $\ldots \ldots \ldots \ldots \ldots \ldots-6 \%$

7) uma nota para o grupo todo $\ldots \ldots \ldots \ldots \ldots \ldots \ldots \ldots \ldots-3 \%$

8) desvalorização do trabalho individual $\ldots \ldots \ldots \ldots \ldots \ldots \ldots-3 \%$

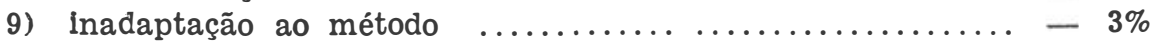


XAVIER, I.B. - O estudo em grupo como métod) de ensino em Psicologia. Rev. Bras. Enf.; RJ, $28: 65-70,1975$.

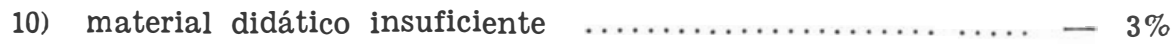

11) temor de não participar adequadamente no grupo $. . . \ldots-3 \%$

h) A seguir relataremos as sugestões apresentadas pelos alunos para resolver os problemas dos grupos:

- mais responsabilidade dos membros (pontualidade, assiduidade) $-31 \%$

- colaboração de todos os membros ................... $13 \%$

- maior entrosamento entre os membros ............... $9 \%$

- orientação individual dos membros .................. $6 \%$

- mudança de equipe ............................. $4 \%$

- motivar cada membro (para o estudo em grupo) ....... - $4 \%$

- mudar o horário aas aulas, separar as amigas, fazer trabalho

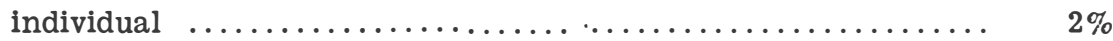

Obs. não apresentaram sugestões $-28 \%$

\section{VI - AVALIAÇÃO DA \\ APRENDIZAGEM}

O regimento interno da Escola de Enfermagem, rezava que as disciplinas anuais deveriam apresentar duas notas correspondentes a exercícios escolares e uma nota correspondente a estágio. Como em Psicologia os alunos não tinham estágio, deveríamos escolher um trabalho equivalente, isto é, que representasse maior empenho e originalidade por parte do aluno.

Selecionamos dois trabalhos realizados durante o $1^{\circ}$ semestre (feitos em grupo), e dois realizados no $2 .^{\circ}$ semestre (estudo teórico em grupo e redação final individual); destes últimos, obtivemos a nota de estágio.

$O$ resultado final fol o seguinte: 32 alunos passaram por média, isto é, obtiveram a média 7 nos trabalhos apresentados; 14 realizaram exame final, tendo 12 alunos sido aprovados; 2 alunos se submeteram ao exame de 2 . $^{\text {a }}$ épca e foram aprovados.

\section{FATORES NEGATIVOS QUE INFLUIRAM NEGATIVAMENTE OU IMPEDIRAM UM RENDIMENTO MAIOR POR PARTE DO GRUPO}

1. Sala de aula - o estudo em grupo requer uma sala de aula adequada. a fim de facilitar a supervisão do professor e o desempenho dos alunos;

2. Bibliografia - uma condição básica para o estudo em grupo é uma bibliografia rica em qualidade e em quantidade, principalmente quando se lida com uma turma numerosa;

3. Duração das aulas - o estudo em grupo requer tempo; somos de parecer que, para maior rendimento dos alunos, se procure concentrar o número de horas de aula (no máximo 3 horas).

\section{VII - ORIENTAÇÃO}

\section{PSICOPEDAGÓGICA}

De início alguns alunos nos procuraram informalmente, para conversarmos sobre a Escola, o método utilizado por nossa disciplina, problemas pessoais, etc. Achamos necessário avisar a toda turma que em determinados horários teríamos prazer em receber quem precisasse de ajuda. Foi muito proveitosa a experiência, realizamos várias entrevistas individuais com alunos, com os grupos de per si e com os representantes dos grupos. Estes encontros se mostraram particularmente úteis para identificarmos os motivos dos alunos isolados, rejeitados pelos colegas e pos- 
XAVIER, I.B. - O estudo em grupo como método de ensino em Psicologia. Rev. Bras.

Enf.; RJ, $28: 65-70,1975$.

teriormente para integrá-los numa equipe.

\section{VIII - CONCLUSÕES}

O método de estudo em grupo revelou-se de agrado da turma e foi considerado como ótimo $(55 \%)$ e bom $(41 \%)$.

A freqüência à biblioteca melhorou consideravelmente, no que se refere a consultas, comparados os anos de 1968 e 1969 .

no ano de 1969: $\quad$ consultas -199 empréstimos - 374

no ano de 1968: $\quad$ consultas -90 empréstimos - 426

Obs. - Segundo informações da bibliotecária, vários livros foram emprestados e anotados apenas como uma saída, durante várias semanas, para servir a muitos alunos, que tinham de pesquisar a mesma área de estudo e permutavam entre si. Daí a aparente baixa nos empréstimos.

Ter ou não experiência anterior em trabalho de grupo não se revelou um dado significativo ou, pelo menos, explicativo das constantes mudanças na composição dos grupos, principalmente durante $01 .^{\circ}$ semestre. Alunos, que afirmaram ter tido experiência anterior em trabalho de equipe, participaram de mais equipes do que os alunos que nunca trabalharam em grupo.

Um fato muito significativo é que a grande maioria dos alunos estavam adaptados aos seus grupos $(85 \%)$, todavia referiam problemas. Os alunos que se diziam adaptados se mostraram muito mais objetivos, portanto, conscientes da situação.

Em suma, eles tinham problemas, mas se entrosavam razoavelmente entre si; enquanto os não adaptados, minoritários, demonstraram como era de se esperar, um alto índice de falta de entrosamento $(40 \%)$ seguido de outros motivos secundários.

Ser entrosado no grupo não era tudo, fazia-se necessário, para o bom andamento dos trabalhos, encarar com responsabilidade os estudos: pontualidade e assiduidade, faziam parte do conjunto das exigências apresentadas pelos grupos (adaptados e não adaptados). Também foi lembrado que em estudo de grupo todos deveriam dar sua parcela de colaboração. Certos alunos ainda mencionaram a necessidade de serem orientados do ponto de vista psicopedagógico, para melhor efetividade da aprendizagem individual e grupal.

As vantagens de se estudar em grupo foram sentidas pelos alunos e bem comunicadas; maior interesse, maior participação dos alunos na matéria e, consequentemente, melhor aprendizagem. Ao mesmo tempo, os alunos verbalizaram que uma grande finalidade do método era socializá-los entre si. Chegaram mesmo a afirmar que o método concedia oportunidade de conhecimento mútuo e de melhorar personalidade individual.

Acreditamos que os nossos objetivos iniciais foram atingidos; a técnica de estudo de grupo por nós utilizada, revelou-se eficiente e válida do ponto de vista dos alunos e do nosso.

Não existe mistério em conduzir um trabalho em equipe; disciplinas afins à Psicologia poderiam se beneficiar do estudo em grupo.

\section{BIBLIOGRAFIA}

1. ALVARENGA, Galeno e Beraldo, W.T. - Ensino não diretivo de Fisiologia in Ciência e Cultura, vol. $19, \mathrm{n}^{\circ} 3$, set. 67 , SP.

2. ANTUNES Celso - Técnicas Pedagógicas de dinâmica de grupo, Edit. do Brasil, S.A. (s.d.)
3. DORIN, Lannoy - Estudo comparativo de métodos de ensino da Psicologia Teórica in Ciência e Cultura, ed. zoologia, vol. 21 , mar. 69, n. ${ }^{\circ}$, SP.

4. PERETTI André - Liberté et Relations Humaines, ed. l'epi, Paris, 1966. 